The Auk 120(4):961-969, 2003

\title{
NOVEL INTRON PHYLOGENY SUPPORTS PLUMAGE CONVERGENCE IN ORIOLES (ICTERUS)
}

\author{
Eva Sanders Allen ${ }^{1,3}$ and Kevin E. Omland ${ }^{2}$ \\ ${ }^{1}$ Center for the Integrative Study of Animal Behavior, and Department of Biology, Indiana University, \\ 1001 East Third Street, Bloomington, Indiana 47405-7005, USA; and \\ ${ }^{2}$ Department of Biological Sciences, University of Maryland Baltimore County, 1000 Hilltop Circle, Baltimore, \\ Maryland 21250, USA
}

\begin{abstract}
Aвstract. - A recent study of New World orioles (Icterus spp.), which traced a large number of plumage characters onto a mitochondrial DNA phylogeny, reported high frequencies of evolutionary convergence and reversal of plumage characters (Omland and Lanyon 2000). Although those results are consistent with other smaller scale studies that have documented plumage homoplasy, the mitochondrial genome is inherited as a single linkage group, so mitochondrial data represent only one gene tree. The mitochondrial $(\mathrm{mt}) \mathrm{DNA}$ tree may not reflect the true evolutionary history of a lineage; therefore, it remains possible that the plumage characters could reflect the true species phylogeny. Other rapidly evolving regions of DNA can provide independent phylogenetic hypotheses useful for evaluating mitochondrial gene trees. A novel phylogenetic marker, a region of the nuclear gene ornithine decarboxylase (ODC) spanning from exon 6 to exon 8, was sequenced in 10 oriole species. The resultant nuclear gene tree reconstructs the same three major oriole clades as the mtDNA tree (Omland et al. 1999), supporting the conclusion that plumage evolution in the New World orioles has been highly homoplastic. Although most phylogenetic studies that have employed introns report greatest resolution at the genus or family level, ODC appears to offer some degree of phylogenetic resolution for infrageneric analyses. However, that intron has clearly not sorted to monophyly within or between closely related species. Received 30 May 2002, accepted 20 April 2003.
\end{abstract}

\begin{abstract}
Resumen. - Un estudio reciente de Icterus, que analizó la evolución de un gran número de caracteres del plumaje sobre una filogenia basada en ADN mitocondrial, documentó una alta frecuencia de convergencias y reversiones evolutivas en caracteres del plumaje (Omland y Lanyon 2000). Aunque esos resultados son consistentes con otros estudios a menor escala que han reportado homoplasia en el plumaje, el genoma mitocondrial se hereda como un solo grupo de ligamiento, por lo que los datos mitocondriales representan sólo un árbol génico. Como el árbol de ADN mitocondrial podría no reflejar la verdadera historia evolutiva de un grupo, es aún posible que los caracteres de plumaje reflejen la filogenia real de las especies. Otras regiones de ADN que evolucionan rápidamente pueden proveer hipótesis filogenéticas independientes de utilidad para evaluar los árboles de genes mitocondriales. Un marcador filogenético nuevo, una región del gen nuclear ODC ("ornithine decarboxylase") que va del exón 6 al exón 8 , fue secuenciada para 10 especies de Icterus. El árbol resultante del gen nuclear reconstruye los mismos tres clados principales de Icterus que el árbol de ADNmt (Omland et al. 1999), apoyando la conclusión de que la evolución del plumaje en Icterus ha sido altamente homoplásica. Aunque la mayoría de los estudios que han empleado intrones documentan una resolución máxima al nivel de género o familia, ODC parece ofrecer algún grado de resolución filogenética para análisis infragenéricos. Sin embargo, este intrón claramente no se ha separado hasta la monofilia entre o dentro de especies estrechamente relacionadas.
\end{abstract}

Avian plumage traits are widely believed to evolve rapidly, with high levels of homoplasy (reviewed in Omland and Lanyon 2000). To test those assumptions, Omland and Lanyon (2000) used a robust, well-resolved mitochondrial (mt) DNA phylogeny of the New World

${ }^{3}$ E-mail: evaallen@indiana.edu orioles (Omland et al. 1999) to test the plasticity of plumage evolution of 44 plumage character traits across 45 oriole taxa. Only two characters showed no homoplasy and were entirely consistent with the molecular phylogeny, and those characters were informative only at the species level. All other characters showed some degree of homoplasy. Further, two overall plumage types termed "Baltimore" and "Altamira" by 
Omland and Lanyon (2000) each appear to have arisen convergently in several clades of the New World orioles. The Baltimore plumage pattern is shared by Icterus galbula (Baltimore Oriole) and I. parisorum (Scott's Oriole) in clade C and I. spurius (Orchard Oriole) in clade A, as the clades are defined by Omland et al. (1999). The Altamira plumage pattern is represented in all three clades, shared by I. gularis (Altamira Oriole, clade C), I. pectoralis (Spot-Breasted Oriole, clade B), and I. cucullatus (Hooded Oriole, clade A). Although homoplastic plumage evolution has been reported in other studies (e.g. Burns 1998, Crochet et al. 2000), the striking similarities among orioles within the Baltimore and Altamira plumage types could be interpreted to cast doubt upon the reliability of the mtDNA phylogeny. That potential conflict between molecular and plumage data has prompted us to construct an independent oriole phylogeny using nuclear intron data, with which we can address the accuracy of the mtDNA phylogeny and more rigorously test Omland and Lanyon's (2000) hypothesis of the evolutionary history of oriole plumage.

The qualities of rapid evolution and uniparental inheritance have made the mitochondrial genome a valuable tool for phylogenetic analyses. The small effective population size of the mitochondrial genome, relative to nuclear genes, means that mtDNA trees have a better chance of tracking the species tree than any single nuclear gene tree (Moore 1995). However, because the mitochondrion is inherited as a single linkage group, mtDNA data yield only one gene tree. As with any single-gene tree, an mtDNA phylogeny has some probability, because of retained ancestral polymorphism and incomplete lineage sorting, that it does not reflect the true evolutionary history of the lineage (Neigel and Avise 1986, Pamilo and Nei 1988, Avise 1989, Moore 1995). That problem has led to the suggestion that species trees are best inferred from several independent gene trees (Pamilo and Nei 1988, Wu 1991).

To build gene trees independent of mtDNA data at lower taxonomic levels, researchers have turned to nuclear introns. Released from many selection pressures constraining the evolution of exons, introns are free to accumulate mutations much more rapidly than coding regions of nuclear (n) DNA, although generally not as rapidly as mtDNA (Shapiro and Dumbacher
2001). That quality potentially bridges a gap between the species-level phylogenetic reconstruction possible with mtDNA data and deeper level phylogenetic reconstructions from coding regions of the nuclear genome. Further, mutations can occur uniformly across introns, rather than mainly at third positions in coding sequences, which may minimize the problem of multiple hits, saturation, and homoplasy associated with mtDNA data (Griffiths 1997). Still, nuclear genes sort much more slowly than mitochondrial genes (Palumbi et al. 2001), which limits the utility of introns for species-level analyses. Using several introns might generate sufficient data for such analyses; however, few avian studies have used nuclear introns to determine levels of mtDNA divergence and taxonomic hierarchy at which nuclear introns sort to monophyly.

Several nuclear introns have been reported to be useful for lower level avian systematics. One of the first developed - and the most widely used thus far-is intron 7 of $\beta$-fibrinogen (Prychitko and Moore 1997). Prychitko and Moore (1997, 2000) sequenced the mitochondrial gene cytochrome $b$ (cyt $b$ ) and intron 7 of the nuclear gene $\beta$-fibrinogen (fib7) in several woodpecker genera. Trees for the two regions are nearly identical, differing at only one deep node. An investigation of eight closely related dove species (Johnson and Clayton 2000a) suggests that fib7 evolves too slowly to resolve infrageneric phylogenies, although intron data did share a deep node with the cyt- $b$ mitochondrial tree and were not inconsistent with the mitochondrial data. Recent studies of adenylate kinase intron 5 (Shapiro and Dumbacher 2001) and avian ovomucoid intron G (Armstrong et al. 2001) report that those introns too are useful at the genus and family level; they show less base-composition bias, little among-site rate heterogeneity, and lower transition-transversion ratios than mitochondrial genes. Developing tractable nuclear introns in different parts of the genome will enable avian systematists to (1) test for congruence among independent nuclear regions, (2) add data for fine-scale resolution, and (3) find introns with different molecular properties (e.g. rates of evolution) that may be useful at different levels of divergence.

Friesen et al. (1999) developed primer pairs for five intron regions, for which they assessed amplification performance and product varia- 
tion in vertebrates, including birds. However, they did not test the phylogenetic utility of those introns. Here, one of those primer pairs was used to reconstruct the phylogeny of a nuclear marker that we term ODC6/7, an intron complex of ornithine decarboxylase (ODC) that targets introns 6 and 7. The phylogenetic resolution that we achieved from ODC sequences was compared within the genus Icterus with that of the mtDNA phylogeny discussed above (Omland et al. 1999) to test the hypothesis that two plumage patterns - the Baltimore type and the Altamira type-have evolved convergently within the New World orioles (Omland and Lanyon 2000). The molecular evolutionary patterns of introns were also compared to those of cyt $b$. Our study represents the first attempt at phylogenetic reconstruction using ODC, a gene implicated in regulating the biosynthesis of polyamines involved in cell growth, development, and division (Yao et al. 1995).

\section{Methods}

DNA sequencing. - To identify an intron useful for reconstructing the phylogeny of Icterus, an array of introns was screened for which universal or avianspecific primers have been published. Primers were initially surveyed for introns of aldolase, $\alpha$-enolase, glyceraldehyde-3-phosphate dehydrogenase (Friesen et al. 1997), adenylate kinase (Shapiro and Dumbacher 2001), $\beta$-fibrinogen (Prychitko and Moore 1997), and ODC (Freisen et al. 1999). The primer sets for ODC and fib7 readily amplified products of a single size, and for those a series of test amplifications were run under varying annealing temperatures and $\mathrm{MgCl}_{2}$ conditions to optimize the polymerase chain reaction (PCR) protocol. Initial sequence data suggested relatively little variation among our study taxa for fib7; therefore, our attention was focused on ODC6/7.

Polymerase chain-reaction primers designed by Friesen et al. (1999; OD6: 5'-GAC TCC AAA GCA GTT TGT CGT CTC AGT GT-3' and OD8: 5'-ATT GGT GGT GGC TTC CCT GGC TCT GAA GA-3') were used to amplify a fragment of ODC stretching from exon 6 to exon 8, which varies in size from 714 to 728 base pairs (bp) among the 16 individuals we sequenced, representing 10 Icterus species (see Table 1). Taxa were chosen that represent each of the three major mtDNA clades of Icterus (Omland et al. 1999), as well as representatives of the two plumage types (Omland and Lanyon 2000). To sequence through the ODC fragment, internal primers in two regions of intron 7 were designed that were relatively conserved among our study taxa (OD6int: 5'-GTT CTA CTT TCT CTG GAA CTA CTG CTC-3' and OD8int: 5'-CAT CAA GTC AGT GAC TTA GCT AGC T-3').

The QIAamp DNA Mini kit (Qiagen, Valencia, California) or the DNeasy tissue kit (Qiagen) was used for DNA extractions. Polymerase chain reaction amplifications were performed with the following temperature profile: initial denaturation at $95^{\circ} \mathrm{C}$ for 4

TABLE 1. Icterid species examined, GenBank accession numbers, and tissue voucher or field numbers.

\begin{tabular}{|c|c|c|c|}
\hline Species/individual & Common name & $\begin{array}{c}\text { ODC GenBank } \\
\text { accession number }\end{array}$ & $\begin{array}{l}\text { Tissue voucher } \\
\text { or field number }\end{array}$ \\
\hline Icterus abeillei & Black-backed Oriole & AF491979a & MZFC KEO28b \\
\hline I. bullockii 1 & Bullock's Oriole & $\begin{array}{l}\text { A:AF491980 } \\
\text { B: AF491981a }\end{array}$ & UWBM 55978 \\
\hline I. bullockii 2 & & AF491982 & UWBM 59055 \\
\hline I. cucullatus & Hooded Oriole & AF491983a & MZFC KEO11 \\
\hline I. dominicensis & Black-cowled Oriole & AF491984a & MZFC KEO18 \\
\hline I. galbula 1 & Baltimore Oriole & AF491985a & UKNHM 90711 \\
\hline I. galbula 2 & & AF491986 & UKNHM 90712 \\
\hline I. galbula 3 & & AF491987 & UKNHM 90713 \\
\hline I. gularis & Altamira Oriole & AF491988a & MZFC KEO 22 \\
\hline I. mesomelas & Yellow-tailed Oriole & AF491989a & BMNH KEO14 \\
\hline I. pectoralis & Spot-breasted Oriole & AF491990a & BMNH KEO08 \\
\hline I. pustulatus & Streak-backed Oriole & $\begin{array}{l}\text { A: AF491991a } \\
\text { B: AF491992 }\end{array}$ & MZFC KEO36 \\
\hline I. spurius 1 & Orchard Oriole & AF491993a & MZFC KEO23 \\
\hline I. spurius 2 & & AF491994 & MZFC KEO24 \\
\hline I. spurius 3 & & AF491995 & MZFC KEO25 \\
\hline I. spurius 4 & & AF491996 & MZFC KEO26 \\
\hline
\end{tabular}


min; 35 cycles of $95^{\circ} \mathrm{C}$ for $60 \mathrm{~s}, 55-60^{\circ} \mathrm{C}$ for $60 \mathrm{~s}, 72^{\circ} \mathrm{C}$ for $45 \mathrm{~s}$; and a final elongation at $72^{\circ} \mathrm{C}$ for $10 \mathrm{~min}$. Annealing temperature was optimized to avoid amplification of paralogous sequences. Initial amplifications were performed in $10 \mu \mathrm{L}$ of a reaction mix comprising $30 \mathrm{mM}$ tricine, $50 \mathrm{mM} \mathrm{KCl}, 2.0 \mathrm{mM} \mathrm{MgCl}_{2}$, $50 \mathrm{mM}$ dNTPs, $0.2 \mu \mathrm{m}$ each flanking primer, and 0.5 $\mathrm{U}$ Taq polymerase, with or without $2.5 \%$ acetamide. Polymerase chain reaction products were cleaned with the QIAquick PRC purification kit (Qiagen) in preparation for sequencing. Cycle sequencing was performed in quarter-volume reactions using Big Dye chemistry (Applied Biosystems, Foster, California). A total of four sequencing reactions for ODC6/7 for each PCR amplification product were sufficient to sequence both strands. Products of sequencing reactions were cleaned by isopropanol precipitation before analysis on an ABI 310 automated DNA capillary sequencer.

Analysis.-Sequence chromatograms were assembled and edited using SEQUENCHER 4.1 (Genecodes Corporation, Ann Arbor, Michigan). For taxa with apparently polymorphic sites in which only one individual was sequenced and the homozygous state was therefore unknown, IUPAC symbols were used to denote polymorphic bases. Because the I. pustulatus ODC complex possessed several polymorphic sites, one allele was assigned to the base shared by the majority of other taxa at each variable site, with the alternate base at those sites composing a second allele. For taxa in which more than one individual was sequenced, according to Clark's (1990) method of allele "subtraction," alleles present in heterozygous individuals were inferred by defining the second allele as the base alternative to that present in homozygous individuals of the same species at each site that produced clean, multiple-base calls of comparable signal intensity. Sequences have been deposited in GenBank under accession numbers AF491979-AF491996 (Table 1).

Insertions and deletions (indels) in the dataset were easily aligned and were treated as single gaps regardless of the length of the indel (after Prychitko and Moore 2000). The criterion of equally weighted parsimony was used to analyze the data, because indels cannot be modeled together with DNA sequence evolution; consequently, widely used programs - such as PAUP* (test version 4.0b8a; Swofford 2001), which we used for all phylogenetic analyses-do not permit the use of model-based approaches with a dataset that includes indels. Given that the ODC intron shows a low number of changes among taxa, and that maximum parsimony and maximum likelihood produce similar results when there is a low probability of character change during the evolution of a group (Felsenstein 1973), the utility of including indels in the analyses reasonably justifies our use of maximum parsimony. Branch and bound searches were conducted with equal character weighting, and multistate characters interpreted as polymorphisms. Because no nucleotide variation exists within any indel region, each gap was scored as present or absent for a given taxon, and then included in analyses as a single character treated as a fifth base. Bootstrap support was assessed using 1,000 pseudoreplicates of the branch and bound search. Our main goal was to test the overall congruence between the mitochondrial and intron sequence data; therefore, all trees were rooted by midpoint and no outgroup species were sequenced.

In addition to analyzing the ODC sequences generated for our study, plumage data from Omland and Lanyon (2000) and cyt-b sequence data from Omland et al. (1999) were also used for analyses of the 10 taxa common to the three studies (cyt $b$ GenBank accession numbers: AF099278, AF099284, AF099289, AF099290, AF099293, AF099300, AF099304, AF099306 and AF099307; I. abeillei, K. E. Omland unpubl. data). For those comparisons, the complete ODC dataset was pruned to a single, arbitrarily chosen individual from each Icterus taxon (indicated in Table 1). Separate tests indicate that the choice of individual did not affect the results. Analyses of the combined dataset were run both with and without the indels, for the cyt- $b$ and ODC data partitioned separately and combined.

\section{Results}

Molecular properties of ornithine decarboxylase.In the 728 bp ODC complex we sequenced, three indels ranging from 1 to $11 \mathrm{bp}$ in length were identified. Twelve bases and all three indels provided phylogenetically informative characters for parsimony analysis of the complete ODC dataset. Because the very few variable sites in the exon regions of ODC were uninformative, all analyses presented for ODC are based upon the $532 \mathrm{bp}$ in introns 6 and 7, with the remaining 196 exon base pairs omitted. Comparisons of ODC to cyt $b$ included 920 bp of cyt- $b$ sequence (from Omland et al. 1999) for one representative allele chosen arbitrarily from each species. Ten nucleotides and two indels in the ODC complex remained phylogenetically informative for those comparisons; sequences of cyt $b$ contained 92 parsimonyinformative characters. Variable sites are much more frequent in cyt $b$ than in the ODC introns. About half of variable sites in both cyt $b$ and ODC are informative for parsimony analyses (92 of 196 sites for cyt $b$ and 12 of 24 sites for ODC), in line with values reported for cyt $b$ by other researchers (Johnson and Clayton 2000b, Prychitko and Moore 1997, 2000).

Nonindependence due to common ancestry prevents rigorous statistical comparisons between the substitution patterns of ODC 
and cyt $b$; however, qualitative investigation provides insight into the processes of molecular evolution acting upon the two regions. Transition substitutions are plotted against transversion substitutions in Figure 1 for all species-pair comparisons. The cyt- $b$ ratio of 5.80 is consistent with other published values for cyt $b$ (Johnson and Clayton 2000b, Moore and DeFilippis 1997). Although not as extreme as that of cyt $b$, the transition-transversion ratio for ODC intron sites is 2.85 , similar to the ratio reported for avian ovomucoid intron $G$ (Armstrong et al. 2001).

That pattern of extreme values for cyt $b$ with more moderate values for ODC introns is also evident in comparisons of molecular distance, as illustrated in Figure 2. Distances for cyt $b$ are considerably greater than ODC values (Fig. 2 ). When cyt- $b$ substitutions are separated into synonymous and nonsynonymous mutations (Fig. 2), it is clear that the elevated substitution rate of cyt $b$, relative to the introns, can be attributed to synonymous mutations. Nonsynonymous cyt- $b$ substitutions fall near the line of equal rates of mutation in Figure 2, which suggests that the overall mutation rate for introns is roughly equivalent to the rate of nonsynonymous mutations in coding regions of the mitochondrial genome. In keeping with the selection pressures constraining evolution of coding DNA, $\sim 80 \%$ of all cyt- $b$ variable sites are located at the third position of a codon; whereas variable sites in ODC introns occur with almost equal frequency across all three positions if the sequence is split arbitrarily into triplets $(30,40,30 \%)$.

Implications for oriole phylogeny. - Sequences of multiple individuals from I. galbula, I. bullockii, and I. spurius permit us to investigate intraspecific, as well as interspecific, variation within ODC. In each species for which we sequenced more than one individual, multiple alleles were found, present in both the heterozygous and homozygous state. We identified two alleles in three homozygous $I$. galbula, three alleles in one heterozygous and one homozygous I. bullockii, and two alleles in four homozygous I. spurius (Table 1). The variation within I. spurius is particularly interesting because individuals 1 and 3 are identical and vary from individual 2 by only 1 bp; whereas they vary from individual 4 by an 11 bp deletion that is shared only by I. mesomelas. In the seven species for which we sequenced only one

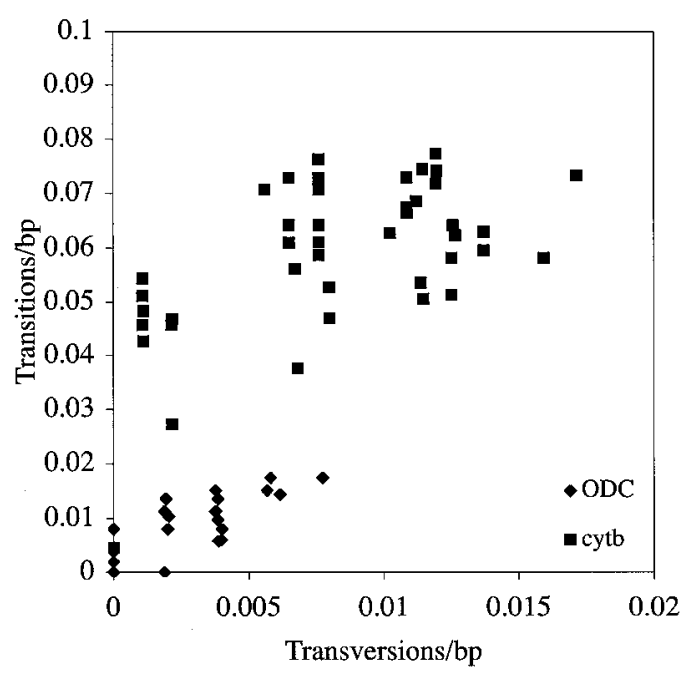

FIG. 1. Scatter plot of transitions as a function of transversions for ODC introns and cyt $b$.

individual, I. pustulatus was clearly heterozygous, varying at eight sites across the fragment we sequenced; however, all other individuals sequenced in the study appeared to be homozygous. The variation we detected within that set of species for which multiple individuals were sequenced is not sufficient to resolve trees composed solely of individuals from two species within a clade but can resolve trees of in-

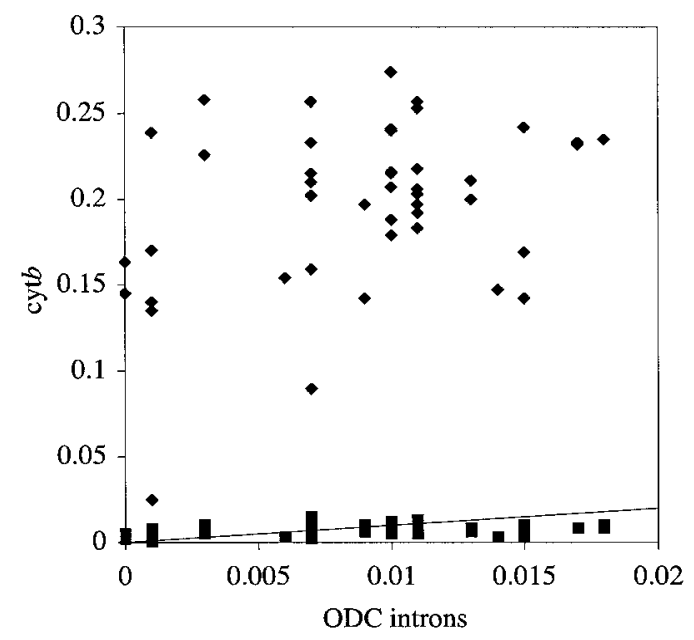

FIG. 2. Species-pair sequence divergence. Diamonds represent synonymous cyt- $b$ substitutions; squares represent nonsynonymous cyt- $b$ substitutions. The line indicates expectation given equal rates of evolution. 
dividuals from two species in different clades. For example, an analysis of all I. bullockii and $I$. galbula sequences fails to resolve the alleles into two taxa; however, an analysis of all I. bullockii and I. spurius alleles fully separates the two taxa with $100 \%$ bootstrap support. That pattern of resolution, at the level of the clade but not within clades, mirrors the results of analyses of the pruned ODC data set containing a single allele from each taxon and is consistent with lack of nuclear allele sorting predicted by Palumbi et al. (2001), as discussed in the introduction.

Parsimony analysis of the complete set of ODC sequences, including indels, results in four equally most-parsimonious trees, of which one is presented in Figure 3. Exclusion of indels increases the number of most-parsimonious trees identified (from 4 to 14) and collapses clades A and B into an unresolved polytomy (not shown); because indels provide additional resolution to those analyses, they are included as single characters classified as a fifth base for all remaining ODC analyses. The ODC6/7 intron complex reconstructs the same three major clades and assigns all species to the same clades as do the mtDNA data (Fig. 4). When ODC and cyt- $b$ sequences are combined into a single dataset, the resulting tree is identical to the cyt- $b$ tree depicted in Figure 4. The ODC tree has a higher rescaled consistency index $(\mathrm{RC}=0.71)$ than the cyt- $b$ tree $(\mathrm{RC}=0.42)$ or the tree generated from the combined dataset $(\mathrm{RC}=0.47)$. The similarity between those latter two rescaled consistency values reflects the heavier representation of $c y t-b$ characters in the combined data set. The pattern of the scatter plot in Figure 2, in which cyt- $b$ sequence divergence levels off with increasing sequence divergence of ODC, suggests that substitutions have accumulated multiple times at the same sites on cyt $b$; that is consistent with our finding that the cyt- $b$ tree has a higher homoplasy index than the ODC tree $(\mathrm{HI}=0.44$ and 0.28 , respectively, excluding uninformative characters).

The three indels detected in ODC are shared among taxa in ways that either define clades or represent apparent homoplasy. One single base pair indel shows no homoplasy, distinguishing clade A from all other taxa. The longest indel is a gap of $11 \mathrm{bp}$ shared as an apparent homoplasy by the only $I$. mesomelas specimen sequenced and one of the four I. spurius individuals sequenced. In another example of apparent ho-

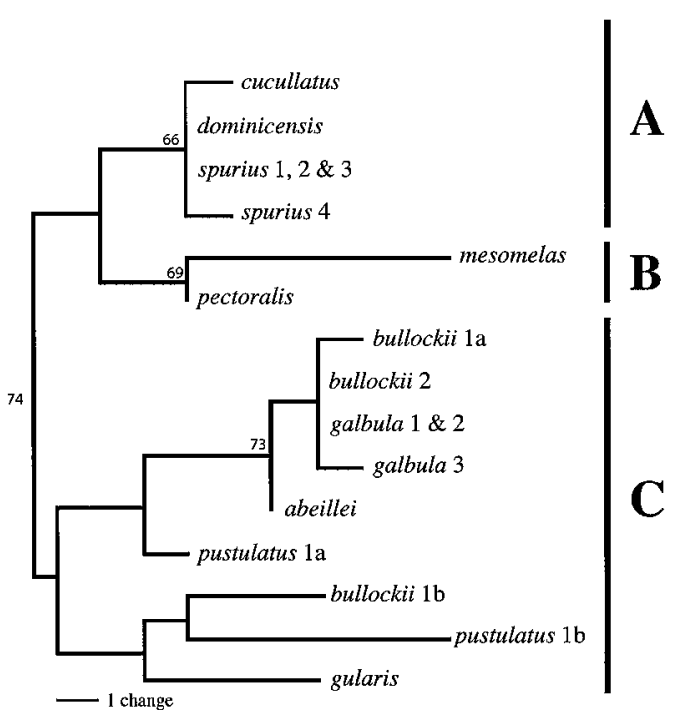

Fig. 3. One of four equally most parsimonious maximum-parsimony topologies for Icterus ODC6/7 intron complex data, including indels, based upon branch and bound searches. Numbers indicate percent bootstrap support from 1,000 branch and bound pseudoreplicates. Bars correspond to the mtDNA clades assigned by Omland et al. (1999).

moplasy, a second 3-bp indel is shared only by clade B taxa and I. gularis.

Plumage convergence.-Complete agreement of the ODC and cytb trees at the clade level lends strong support to the conclusions

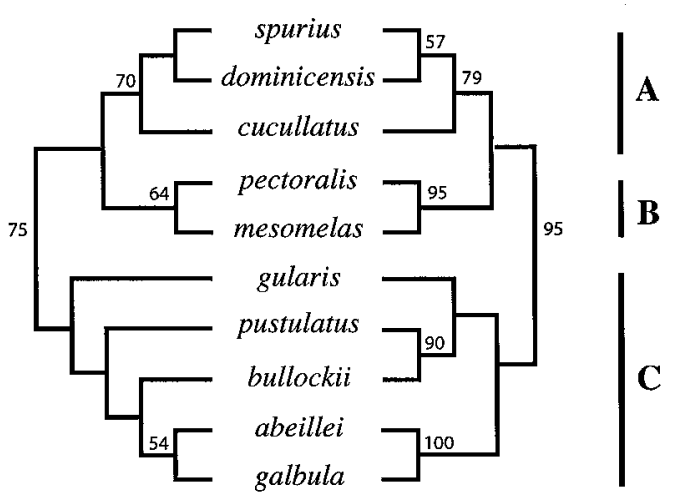

FIG. 4. Maximum-parsimony topologies for the pruned Icterus ODC6/7 intron complex dataset (left) and cyt $b$ (right), from branch and bound searches. Numbers indicate percent bootstrap support based on 1,000 branch and bound pseudoreplicates. Bars demark clades, as assigned by Omland et al. (1999). 


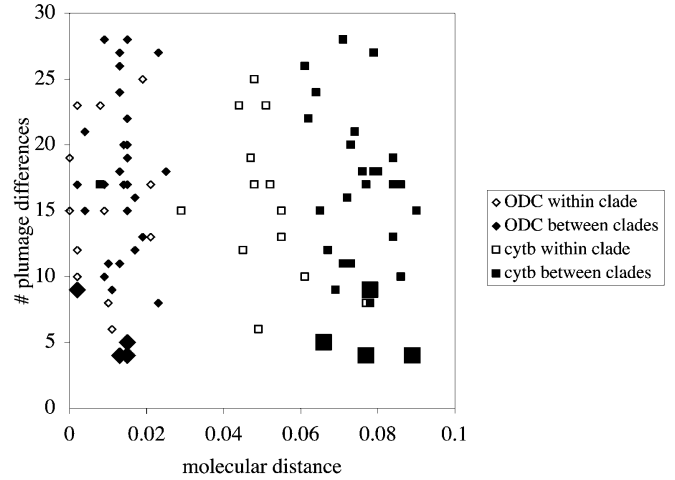

Fig. 5. Absolute number of plumage differences between species pairs, plotted as a function of sequence divergence. Enlarged points correspond to species pairs sharing the Baltimore or Altamira plumage pattern; those species pairs share very similar plumage but show more molecular divergence than many other species pairs with less similar plumage.

presented in Omland and Lanyon (2000) that plumage characters in the New World orioles are homoplastic, and that the Baltimore and Altamira plumage patterns have evolved convergently in separate clades. A broad range of plumage differences can be found at any level of molecular divergence for both ODC and cyt $b$ (Fig. 5). Baltimore and Altamira plumage types are remarkably similar in plumage, yet exhibit more molecular divergence than most species pairs within Icterus.

\section{Discussion}

The phylogenetic utility of cyt $b$ and other mitochondrial coding genes has been well established; however, the tendency of cyt $b$ to accumulate multiple substitutions at the same site can result in homoplasies that degrade phylogenetic signal (Meyer 1994, Griffiths 1997). We demonstrate that the ODC intron complex accumulates substitutions more slowly than cyt $b$ but also more evenly across all positions. Moreover, ODC provides good phylogenetic resolution among clades within a genus. Using $532 \mathrm{bp}$ of intron sequence from the nuclear regulatory gene ODC for 10 species of orioles, a phylogenetic tree was reconstructed with the same three clades as a phylogeny based upon $920 \mathrm{bp}$ of sequence from the mitochondrial gene cyt $b$ (from Omland et al. 1999). That result strongly supports Omland and
Lanyon's (2000) conclusions that the Baltimore and Altamira plumage patterns found in multiple clades of the oriole mtDNA phylogeny result from convergent evolution, and that plumagecharacter evolution is highly plastic within the New World orioles (Fig. 5).

High levels of intraspecific ODC allelic diversity detected from the small sample size included here suggest that ODC may prove useful for intraspecific analyses based upon allele frequencies. For example, two I. galbula ODC alleles were identified in three individuals that share 1 cyt- $b$ haplotype out of 13 identified in the species, and three I. bullockii ODC alleles in two individuals that share 1 cyt- $b$ haplotype out of 7 identified in the species (E. S. Allen unpubl. data). However, our inability to resolve the phylogenetic positions of alleles from taxa within the same clade (i.e. I. galbula and I. bullockii) suggests that those alleles have not sorted to monophyly at the species level. Indeed, it is likely that greater intraspecific sampling would show that ODC alleles are paraphyletic across many closely related species. Palumbi et al. (2001) have demonstrated that the average neutral nuclear locus, such as the introns we examined in this study, will generally still be poly- or paraphyletic when a mitochondrial locus reaches monophyly (also see Moore 1995). It is also likely that some sharing of intron alleles between I. galbula and I. bullockii results from frequent ongoing hybridization (Allen 2002).

Our results clearly demonstrate that the ODC6/7 intron complex is a promising candidate for future phylogenetic analyses, both at the level of genus and above, especially for comparison and combination with other nuclear introns. However, for closely related species it is unlikely that any single nuclear intron will sort fast enough to be useful for building conventional phylogenetic trees. Methods that depend on allele frequencies or that combine data from multiple introns may be needed to test lower order mtDNA phylogenies.

\section{Acknowledgments}

E.S.A. was supported by an American Ornithologists' Union research grant and a National Science Foundation (NSF) Research Training Grant (RTG) fellowship. K.E.O. was supported by NSF grant DEB 0004400. We thank C. Feldman for laboratory assistance and G. Gastony, members of the Rieseberg lab, I. Lovette, and an anonymous reviewer for help- 
ful comments on the manuscript. We are grateful to S. Lanyon, R. Fleischer, R. Greenberg, B. Barber, and M. Robbins for assistance and support with tissue collection. For tissue loans, we thank M. Robbins of the University of Kansas Natural History Museum, and S. Rohwer and S. Birks of the University of Washington Burke Museum. A. N. Sigüenza, S. López de Aquino, and students at the Museo de Zoologia at the National Autonomous University of Mexico provided invaluable assistance in collecting Icterus in Mexico.

\section{Literature Cited}

Allen, E. S. 2002. Long-term hybridization and the maintenance of species identity in orioles (Icterus). Ph.D. dissertation, Indiana University, Bloomington.

Armstrong, M. H., E. L. Braun, and R. T. Kimball. 2001. Phylogenetic utility of avian ovomucoid intron G: A comparison of nuclear and mitochondrial phylogenies in Galliformes. Auk 118:799-804.

Avise, J. C. 1989. Gene trees and organismal histories: A phylogenetic approach to population biology. Evolution 43:1192-1208.

Burns, K. J. 1998. Molecular phylogenetics of the genus Piranga: Implications for biogeography and the evolution of morphology and behavior. Auk 115:621-634.

Clark, A. G. 1990. Inference of haplotypes from PCR-amplified samples of diploid populations. Molecular Biology and Evolution 7:111-122.

Crochet, P. A., F. Bonhomme, and J.-D. Lebreton. 2000. Molecular phylogeny and plumage evolution in gulls (Larini). Journal of Evolutionary Biology 13:47-57.

Felsenstein, J. 1973. Maximum likelihood and minimum-steps methods for estimating evolutionary trees from data on discrete characters. Systematic Zoology 22:240-249.

Friesen, V. L., B. C. Congdon, M. G. Kidd, and T. P. Birt. 1999. Polymerase chain reaction (PCR) primers for the amplification of five nuclear introns in vertebrates. Molecular Ecology 8: 2141-2152.

Friesen, V. L., B. C. Congdon, H. E. Walsh, and T. P. BIRT. 1997. Intron variation in Marbled Murrelets detected using analyses of singlestranded conformational polymorphisms. Molecular Ecology 6:1047-1058.

Griffiths, C. S. 1997. Correlation of functional domains and rates of nucleotide substitution in cytochrome $b$. Molecular Phylogenetics and Evolution 7:352-365.

Johnson, K. P., and D. H. Clayton. 2000a. A molecular phylogeny of the dove genus Zenaida: Mitochondrial and nuclear DNA sequences. Condor 102:864-870.
Johnson, K. P., and D. H. Clayton. 2000b. Nuclear and mitochondrial genes contain similar phylogenetic signal for pigeons and doves (Aves: Columbiformes). Molecular Phylogenetics and Evolution 14:141-151.

Meyer, A. 1994. The shortcomings of the cytochrome $b$ gene as a molecular marker. Trends in Ecology and Evolution 9:278-280.

Moore, W. S. 1995. Inferring phylogenies from mtDNA variation: Mitochondrial-gene trees versus nuclear-gene trees. Evolution 49: 718-726.

Moore, W. S., and V. R. DeFilippis. 1997. The window of taxonomic resolution for avian phylogenies based on mitochondrial cytochrome $b$ DNA sequences. Pages 83-119 in Avian Molecular Evolution and Systematics (D. P. Mindell, Ed). Academic Press, New York.

Neigel, J. E., AND J. C. Avise. 1986. Phylogenetic relationships of mitochondrial DNA under various demographic models of speciation. Pages 515-533 in Evolutionary Processes and Theory (S. Parkin and E. Nevo, Eds.) Academic Press, Orlando, Florida.

Omland, K. E., and S. M. Lanyon. 2000. Reconstructing plumage evolution in orioles (Icterus): Repeated convergence and reversal in patterns. Evolution 54:2119-2133.

Omland, K. E., S. M. Lanyon, and S. J. Fritz. 1999. A molecular phylogeny of the New World orioles (Icterus): The importance of dense taxon sampling. Molecular Phylogenetics and Evolution 12:224-239.

Palumbi, S. R., F. Cipriano, and M. P. Hare. 2001. Predicting nuclear gene coalescence from mitochondrial data: The three-times rule. Evolution 55:859-868.

Pamilo, P., and M. Nei. 1988. Relationships between gene trees and species trees. Molecular Biology and Evolution 5:568-583.

Prychitko, T. M., AND W. S. Moore. 1997. The utility of DNA sequences of an intron from the $\beta$-fibrinogen gene in phylogenetic analysis of woodpeckers (Aves: Picidae). Molecular Phylogenetics and Evolution 8:193-204.

Prychitko, T. M., AND W. S. Moore. 2000. Comparative evolution of the mitochondrial cytochrome $b$ gene and nuclear $\beta$-fibrinogen intron 7 in woodpeckers. Molecular Biology and Evolution 17:1101-1111.

Shapiro, L. H., and J. P. Dumbacher. 2001. Adenylate kinase intron 5: A new nuclear locus for avian systematics. Auk 118:248-255.

Swofford, D. L. 2001. PAUP*. Phylogenetic Analysis Using Parsimony and Other Methods, version 4. Sinauer Associates, Sunderland, Massachusetts.

Wu, C.-I. 1991. Inferences of species phylogeny 
in relation to segregation of ancient polymorphisms. Genetics 127:429-436.

YaO, J., D. Zadworny, U. Kuhnlein, and J. F. Hayes. 1995. Molecular cloning of a bovine ornithine decarboxylase cDNA and its use in the detection of restriction fragment length polymorphisms in Holsteins. Genome 38:325-331.

Associate Editor: R. O. Prum 